\title{
APROVEITAMENTO DO SORO DE RICOTA NA ELABORAÇÃO DE BEBIDA LÁCTEA ACIDIFICADA CARBONATADA
}

\section{Use of ricotta whey in the elaboration of acidified carbonated dairy drink}

\author{
Junio Cesar Jacinto de Paula ${ }^{1 *}$, Juliana Nogueira Boccia ${ }^{1}$, Denise Sobral ${ }^{1}$, Renata \\ Golin Bueno Costal , Gisela de Magalhães Machado Moreiral, Paulo Henrique Costa \\ Paiva $^{1}$,Vanessa Aglaê Martins Teodoro ${ }^{2}$
}

\section{RESUMO}

O soro de ricota, apesar do baixo teor de proteína, é fonte de diversos nutrientes. Contudo, no Brasil ele ainda é utilizado de forma ineficiente ou simplesmente descartado no meio ambiente. $\mathrm{O}$ aproveitamento adequado desse tipo de soro ainda é muito restrito devido à indisponibilidade de conhecimento tecnológico ou falta de interesse da indústria. Porém, nesse tipo de soro, a lactose, sais minerais e vitaminas ainda permanecem, remanescendo, em consequência, grande valor nutricional e também o seu poder poluente. O objetivo deste trabalho foi elaborar uma bebida carbonatada acidificada utilizando soro da fabricação de ricota e determinar sua composição físico-química, qualidade microbiológica e aceitação sensorial. Pela composição físico-química, a bebida láctea desenvolvida enquadrase na legislação como bebida láctea com adição ou bebida láctea com produto ou substância alimentícia. O produto apresentou aceitabilidade sensorial e estabilidade microbiológica durante 60 dias de armazenamento a $5^{\circ} \mathrm{C}$. Assim, existe viabilidade tecnológica e aplicabilidade do aproveitamento sustentável do soro de ricota na elaboração de bebidas lácteas acidificadas carbonatadas. A utilização desse tipo de soro pode incentivar o consumo de lácteos melhorando a nutrição das pessoas além de reduzir problemas ambientais, podendo aumentar a receita e a competitividade produtiva das indústrias.

Palavras-chave: precipitação ácida; inovação; poluição; estocagem refrigerada.

1 Empresa de Pesquisa Agropecuária de Minas Gerais, Instituto de Laticínios Cândido Tostes, Rua Tenente Luiz de Freitas, 116, Santa Terezinha, 36045-560, Juiz de Fora, MG, Brasil. E-mail: junio@epamig.br

2 Universidade Federal de Juiz de Fora, Departamento de Medicina Veterinária, Juiz de Fora, MG, Brasil.

* Autor para correspondência 


\begin{abstract}
Ricotta whey, despite its low protein content, is a source of many nutrients. However, in Brazil it is still used inefficiently or simply discarded in the environment. The adequate use of this type of whey is still very restricted due to the unavailability of technological knowledge or lack of interest in the industry. However, in this type of whey, lactose, mineral salts, and vitamins still remain, consequently remaining a great nutritional value and also its polluting capacity. The objective of this work was to elaborate an acidified carbonated drink using ricotta whey and to determine its physical-chemical composition, microbiological quality and sensory acceptance. Due to its physical-chemical composition, the developed milk drink fits into the legislation as a dairy drink with addition or dairy drink with food product or substance. The product showed sensory acceptability and microbiological stability during 60 days of storage at $5^{\circ} \mathrm{C}$. Thus, there is technological feasibility and applicability of the sustainable use of ricotta whey in the production of carbonated acidified dairy drinks. The use of this type of whey can encourage the consumption of dairy products by improving people's nutrition, in addition to reducing environmental problems, which can increase the profits and the productive competitiveness of industries.
\end{abstract}

Keywords: acid precipitation; innovation; pollution; refrigerated storage.

\section{INTRODUÇÃO}

O nome ricota é derivado da palavra latina "recocta" que significa cozido duas vezes. É um queijo suave, não maturado, que foi originalmente produzido na Itália com leite de ovelha. $\mathrm{Na}$ atualidade, atingiu maior popularidade, sendo elaborado de soro ou de mistura de soro e leite bovino pasteurizado integral ou desnatado. O princípio de sua fabricação é baseado na precipitação das proteínas do soro ( $\alpha$-lalctoalbumina e $\beta$-lactoglobulina) por meio de calor associado à acidificação (BRUGNERA, 2011).

No Brasil não existe Regulamento Técnico de Identidade e Qualidade para a ricota e a única legislação existente é o Regulamento de Inspeção Industrial e Sanitária de Produtos de Origem Animal (RIISPOA). De acordo com o RIISPOA, ricota fresca é o queijo obtido pela precipitação ácida a quente de proteínas do soro de leite, com adição de leite até $20 \%$ do seu volume (BRASIL, 2017).
O rendimento da sua fabricação situase em torno de $5 \%$ em relação ao volume de soro de queijo utilizado. O soro resultante da fabricação de ricota é composto por 0,15 a $0,22 \%$ de proteínas, 4,8 a $5,0 \%$ de lactose, 1,0 a $1,3 \%$ de sais minerais e 0,20 a $0,25 \%$ de ácidos orgânicos (SANSONETTI et al., 2009).

Em uma quantidade razoável de casos, o soro proveniente da fabricação de queijos é utilizado para a produção da ricota, que é obtida pela coagulação a quente das proteínas e posterior coleta e enformagem da massa. Entretanto, a lactose (sólido mais abundante no soro) permanece, restando, consequentemente, a maior parte responsável pelo poder poluente do soro (RAMOS, 2010). O soro resultante da fabricação da ricota pode possuir gosto ácido e elevado teor salino, o que tem sido um fator limitante para o seu aproveitamento na alimentação humana. Porém, este soro possui características nutricionais importantes (alto teor de lactose, minerais e vitaminas) que podem agregar valor ao desenvolvimento de novos produtos, 
principalmente bebidas lácteas, além de eliminar problemas com descarte inadequado do meio ambiente (ANTUNES, 2003).

De forma equivocada, as indústrias de laticínios consideram que com a produção de ricota estão aproveitando totalmente o soro proveniente da fabricação de queijos. No entanto, na fabricação de ricota é gerado um segundo soro que pode ser ainda mais poluente devido ao $\mathrm{pH}$ mais ácido oriundo da utilização de ácido lático ou outros ácidos orgânicos na coagulação (FURTADO; LOURENÇO NETO, 1994).

Assim, o objetivo do trabalho foi avaliar, em escala piloto, a viabilidade tecnológica e a aplicabilidade do aproveitamento do soro de ricota na elaboração de uma bebida láctea acidificada carbonatada, bem como, avaliar a sua estabilidade e qualidade durante o período de estocagem refrigerada por 60 dias.

\section{MATERIAL E MÉTODOS}

Este estudo foi conduzido nas dependências do Laboratório de Pesquisa, Desenvolvimento e Inovação (Laboratório de PD\&I) da Empresa de Pesquisa Agropecuária de Minas Gerais Instituto de Laticínios Cândido Tostes (EPAMIG ILCT), em Juiz de Fora, Minas Gerais. As bebidas lácteas acidificadas carbonatadas foram fabricadas no Laboratório de PD\&I, enquanto as análises físico-químicas, microbiológicas e sensoriais foram realizadas nos respectivos laboratórios de pesquisa da EPAMIG ILCT.

\section{Delineamento experimental}

No experimento foi utilizado o delineamento experimental em parcelas subdivididas no tempo. Foi utilizada a estatística descritiva, análise de variância (ao nível de 5\% de probabilidade) e regressão para apresentação, avaliação e discussão dos resultados. Todos os dados foram tabulados em planilha eletrônica e, posteriormente, analisados estatisticamente por meio de programa apropriado Minitab, versão 14 (MINITAB Statistical Software $^{\circledR}$ ). As bebidas lácteas foram fabricadas em três repetições (R1, R2 e R3).

\section{Análises experimentais e metodologias}

Após cada fabricação, o produto foi envasado em garrafas de polietileno tereftalato (PET) de $350 \mathrm{~mL}$ e armazenado sob refrigeração $\left(5 \pm 1^{\circ} \mathrm{C}\right)$ para a realização das análises previstas. As análises foram realizadas nos tempos 4, 20, 40 e 60 dias após cada fabricação (Tabela 1), durante o armazenamento sob refrigeração.

Para o leite, o soro e as bebidas lácteas, a acidez titulável foi medida pelo método titrimétrico com solução de hidróxido de sódio $(\mathrm{NaOH})$ 0,1 mol/L até $\mathrm{pH}$ 8,3 e o resultado expresso em $\%(\mathrm{~m} / \mathrm{v}) \mathrm{de}$ compostos ácidos expressos como ácido lático (HELRICH, 1990). A determinação do $\mathrm{pH}$ foi feita utilizando medidor de $\mathrm{pH}$ modelo Tecnal, pH Meter Tec-2. A viscosidade aparente foi determinada pelo método instrumental utilizando viscosímetro rotatório marca Brookfield. As condições do teste foram: eixo rotatório 1 , velocidade de rotação $50 \mathrm{rpm}$, tempo de teste 2 minutos, as amostras foram colocadas em um béquer na quantidade de $500 \mathrm{~mL}$ a $20^{\circ} \mathrm{C}$ (PEREIRA et al., 2001).

As análises dos teores de gordura, sólidos totais, resíduo mineral fixo e nitrogênio total $(\% \mathrm{NT})$ foram realizadas de acordo com os métodos oficiais descritos na Instrução Normativa ${ }^{\circ} 68$, de 14 de abril de 2006 (BRASIL, 2006). O teor de proteína foi calculado a partir da multiplicação da \%NT pelo fator 6,38 (PEREIRA et al., 2001). O teor de carboidratos aproximado foi calculado pela diferença entre o teor de sólidos totais e o somatório de proteína total, gordura e resíduo 
mineral fixo. Todas as análises físico-químicas foram realizadas em duplicata.

Foram realizadas análises microbiológicas para as bebidas lácteas acidificadas carbonatadas para determinação da contagem padrão (aeróbios facultativos e anaeróbios estritos), coliformes a $30^{\circ} \mathrm{C}$ (totais) e a $45^{\circ} \mathrm{C}$ (termotolerantes), fungos filamentosos e leveduras. Utilizou-se técnicas de contagem em placas Petrifilm ${ }^{\circledR}$ (3M do Brasil Ltda.), de acordo com as respectivas metodologias, materiais e com os procedimentos determinados pelo fabricante, sendo indicadas para análises em leite e produtos lácteos (PARK et al., 2004).

$\mathrm{Na}$ avaliação sensorial das bebidas lácteas foram realizados testes de aceitação utilizando a escala hedônica de nove pontos (CHAVES; SPROESSER, 1995; MINIM, 2006). Os testes foram realizados em cada repetição (R1, R2 e R3), após 4, 20, 40 e 60 dias de fabricação dos produtos. Nos testes foi empregado um número mínimo de 30 provadores não-treinados para cada tempo avaliado, totalizando pelo menos 120 testes realizados. Os provadores foram selecionados aleatoriamente entre alunos do curso Técnico em Leite e Derivados da EPAMIG ILCT, com perfil e conhecimento técnico. As amostras avaliadas foram servidas a $5^{\circ} \mathrm{C}$ em copos descartáveis de $50 \mathrm{~mL}$ codificados com números aleatórios de três dígitos.

\section{Obtenção do soro de ricota e elaboração da bebida láctea}

O soro de ricota utilizado para a fabricação da bebida láctea foi obtido segundo metodologia descrita por Furtado; Lourenço Neto (1994). A partir da obtenção do soro foram retiradas amostras para análises físicoquímicas e elaborada a bebida láctea com aproveitamento do soro de ricota segundo fluxograma descrito na Figura 1.

Após a obtenção do soro de ricota, seguiu-se a elaboração das bebidas lácteas com aproximadamente 20 litros de bebida para cada repetição. O soro foi filtrado através

Tabela 1 - Análises físico-químicas, microbiológicas e sensoriais realizadas para o leite, soros e bebidas lácteas durante a estocagem (60 dias)

\begin{tabular}{|c|c|c|c|c|c|c|c|c|c|c|c|}
\hline \multicolumn{12}{|c|}{ Análises } \\
\hline & \multicolumn{8}{|c|}{ Físico-químicas } & \multirow{2}{*}{$\frac{\text { Sensoriais }}{\text { Aceitação }}$} & \multicolumn{2}{|c|}{ Microbiológicas } \\
\hline $\begin{array}{c}\text { Dias de } \\
\text { fabricação }\end{array}$ & $\mathrm{Gb}$ & Acidez & $\mathrm{pH}$ & Visc & RMF & ST & PTN & $\mathrm{CHO}$ & & $\begin{array}{c}\text { Coliformes } \\
30^{\circ} \mathrm{C} \text { e } 45^{\circ} \mathrm{C}\end{array}$ & $\begin{array}{c}\mathrm{CP} \text {, fungos e } \\
\text { leveduras }\end{array}$ \\
\hline \multicolumn{12}{|c|}{ Leite e soro de leite } \\
\hline 0 & $\checkmark$ & $\checkmark$ & $\checkmark$ & & $\checkmark$ & $\checkmark$ & $\checkmark$ & & & & \\
\hline \multicolumn{12}{|c|}{ Bebida láctea acidificada carbonatada } \\
\hline 4 & $\checkmark$ & $\checkmark$ & $\checkmark$ & $\checkmark$ & $\checkmark$ & $\checkmark$ & $\checkmark$ & $\checkmark$ & $\checkmark$ & $\checkmark$ & $\checkmark$ \\
\hline 20 & & $\checkmark$ & $\checkmark$ & $\checkmark$ & & & & & $\checkmark$ & & $\checkmark$ \\
\hline 40 & & $\checkmark$ & $\checkmark$ & $\checkmark$ & & & & & $\checkmark$ & & $\checkmark$ \\
\hline 60 & & $\checkmark$ & $\checkmark$ & $\checkmark$ & & & & & $\checkmark$ & & $\checkmark$ \\
\hline
\end{tabular}

Legenda: Gb - gordura butirométrica; Visc - viscosidade; RMF - resíduo mineral fixo; ST - sólidos totais; PTN proteínas; CHO - carboidratos; $\mathrm{CP}$ - contagem padrão de aeróbios mesófilos; $\checkmark=$ análise realizada. 
de um filtro dessorador para assegurar que nenhuma partícula de queijo fosse incorporada à bebida. Ao soro foi adicionado o leite desnatado com volume ajustado em função do teor de proteína na bebida final, para que ela pudesse ser enquadrada no Regulamento Técnico de Identidade e Qualidade (RTIQ) de Bebida Láctea (BRASIL, 2005).

Os ingredientes sólidos foram adicionados previamente misturados, sendo eles o açúcar, estabilizante e conservante, sob agitação. A temperatura da mistura foi ajustada para $65^{\circ} \mathrm{C}$, sendo em seguida homogeneizada em um homogeneizador industrial de leite de dois estágios, utilizando a mesma pressão indicada para leite $\left(140,62 \mathrm{kgf} / \mathrm{cm}^{2}\right.$ no primeiro estágio e $35,15 \mathrm{kgf} / \mathrm{cm}^{2}$ no segundo estágio). A mistura homogeneizada foi adicionada de corante natural e acidificada até $\mathrm{pH} 4$. Logo após, a bebida foi tratada termicamente a $68^{\circ} \mathrm{C}$ por 12 minutos, segundo Bastos (2016), e rapidamente resfriada a $10^{\circ} \mathrm{C}$. Foi aromatizada com aroma natural e submetida à carbonatação sob pressão. $\mathrm{O}$ produto foi carbonatado entre 50 e $100 \mathrm{kgf} / \mathrm{cm}^{2}$. Após 10 min em contato com o $\mathrm{CO}_{2}$, sob pressão, a bebida foi imediatamente envasada em garrafas PET com capacidade de $350 \mathrm{~mL}$ previamente limpas e sanitizadas em solução a $200 \mathrm{mg} / \mathrm{L}$ de cloro ativo e identificadas. As bebidas engarrafadas foram estocadas sob refrigeração em estufa B.O.D. $\left(5^{\circ} \mathrm{C}\right)$.

\section{RESULTADOS E DISCUSSÃO}

\section{Características físico-químicas e compo- sição centesimal do leite, do soro e das bebidas lácteas}

Os resultados das análises físicoquímicas e composição centesimal do leite e do soro de ricota utilizados para a elaboração das bebidas lácteas, assim como os resultados das análises de composição das bebidas após 4 dias de fabricação, estão apresentados na Tabela 2.

De acordo com a Tabela 2, o teor médio de proteína para as bebidas lácteas elaboradas a partir de soro de ricota $(1,15 \% \mathrm{~m} / \mathrm{v})$ está em conformidade com a Instrução Normativa $\mathrm{n}^{\circ}$ 16, de 23 de agosto de 2005. O teor mínimo de proteína preconizado pela legislação é de $1,0 \%(\mathrm{~m} / \mathrm{v})$ para bebidas lácteas com adição ou bebidas lácteas com produto(s) ou substância(s) alimentícia(s) (BRASIL, 2005).

Foi utilizado um volume maior de soro em relação ao leite, pois um dos objetivos foi fabricar um produto de baixo custo. $\mathrm{O}$ volume de leite foi ajustado em função do conteúdo de proteína final esperado para as bebidas lácteas, para que estas pudessem ser enquadradas na

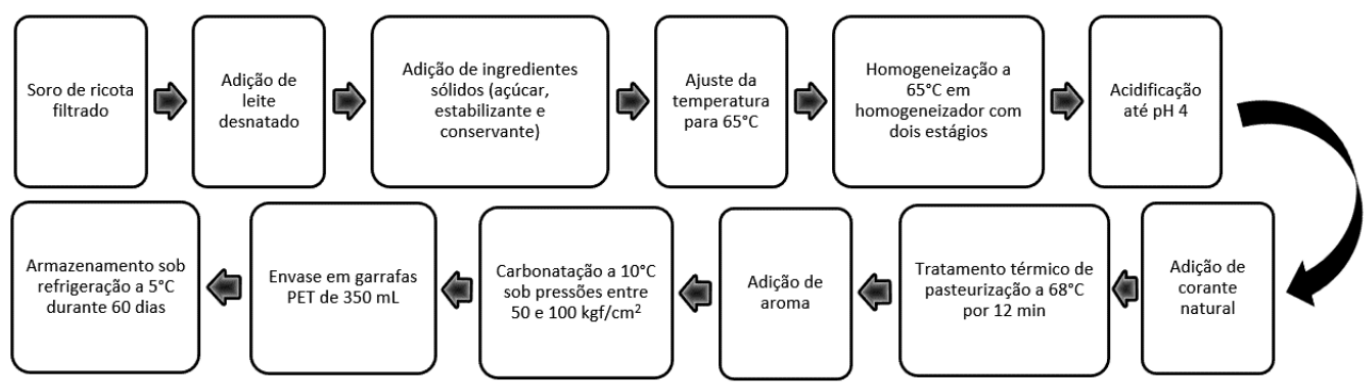

Figura 1 - Fluxograma de fabricação da bebida láctea carbonatada com aproveitamento de soro de ricota 
legislação em relação ao teor proteico mínimo estabelecido pela Instrução Normativa $n^{\circ} 16$, de 23 de agosto de 2005 (BRASIL, 2005).

Devido a utilização de leite desnatado e ao baixo conteúdo de gordura no soro utilizado, os teores médios de gordura nas bebidas foram $0 \%(\mathrm{~m} / \mathrm{v})$. A Instrução Normativa não estabelece os teores referentes à composição centesimal da bebida láctea, à exceção da proteína.

A composição de bebidas lácteas pode variar de acordo com a quantidade de soro empregada e pela metodologia aplicada para sua obtenção. Essa variação pode ser comprovada ao se comparar os resultados do presente trabalho com os encontrados por Bastos (2016), o qual identificou teor médio de proteína de $1,39 \%(\mathrm{~m} / \mathrm{v})$ para bebida láctea acidificada carbonatada aromatizada e enriquecida com luteína. Luiz (2008) e Fontes (2007) encontraram teores de proteína de $1,30 \%(\mathrm{~m} / \mathrm{v})$ e $1,28 \%$ $(\mathrm{m} / \mathrm{v})$ respectivamente para bebidas lácteas tratadas termicamente após fermentação. Teixeira (2002) desenvolveu bebidas lácteas fermentadas com adição de $50 \%$ a $70 \%$ de soro de ricota e encontrou teores de proteína entre 2,05 e $1,73 \%$ e lipídeos entre 0,22 e $0,13 \%$. As bebidas lácteas fermentadas desenvolvidas por Teixeira (2002) foram estáveis por 28 dias.

As bebidas lácteas elaboradas com soro de ricota apresentaram $\mathrm{pH}$ igual a 3,71 após 4 dias de fabricação. Jay et al. (2005) estabeleceu que a maioria dos microrganismos crescem mais acentuadamente em valores de $\mathrm{pH}$ em torno de 7,0 , apesar de alguns fungos filamentosos e leveduras crescerem em $\mathrm{pH}$ abaixo de 4,0. O valor do $\mathrm{pH}$ médio para as bebidas foi definido levando-se em consideração o período de armazenamento de 60 dias sob temperatura de refrigeração, sendo que esse valor de $\mathrm{pH}$ deve se situar abaixo da faixa onde se encontra o crescimento da maioria dos microrganismos indesejáveis.

Tabela 2 - Resultados das análises físico-químicas e da composição centesimal do leite, do soro de ricota e da bebida láctea de soro de ricota (após 4 dias de fabricação)

\begin{tabular}{lccc}
\hline Parâmetro & $\begin{array}{c}\text { Leite } \\
\left(\mathrm{média}^{*} \pm \mathrm{DP}\right)\end{array}$ & $\begin{array}{c}\text { Soro } \\
\left(\mathrm{média}^{*} \pm \mathrm{DP}\right)\end{array}$ & $\begin{array}{c}\text { Bebida láctea } \\
(\text { média* } \pm \mathrm{DP})\end{array}$ \\
\hline Proteína $(\% \mathrm{~m} / \mathrm{v})$ & $3,01 \pm 0,09$ & $0,47 \pm 0,03$ & $1,15 \pm 0,03$ \\
Gordura $(\% \mathrm{~m} / \mathrm{v})$ & $0,13 \pm 0,06$ & $0,00 \pm 0,00$ & $0,00 \pm 0,00$ \\
Umidade $(\% \mathrm{~m} / \mathrm{v})$ & $90,77 \pm 0,10$ & $93,95 \pm 0,02$ & $79,56 \pm 1,71$ \\
EST $(\% \mathrm{~m} / \mathrm{v})$ & $9,23 \pm 0,10$ & $6,05 \pm 0,02$ & $20,44 \pm 1,71$ \\
Carboidrato $(\% \mathrm{~m} / \mathrm{v})$ & $5,35 \pm 0,05$ & $5,09 \pm 0,04$ & $18,80 \pm 1,66$ \\
RMF $(\% \mathrm{~m} / \mathrm{v})$ & $0,75 \pm 0,01$ & $0,49 \pm 0,03$ & $0,48 \pm 0,03$ \\
$\mathrm{pH}$ & $6,72 \pm 0,01$ & $5,83 \pm 0,03$ & $3,71 \pm 0,13$ \\
Acidez titulável $(\% \mathrm{~m} / \mathrm{v})$ & $0,15 \pm 0,01$ & $0,13 \pm 0,02$ & $1,22 \pm 0,17$ \\
Viscosidade $(\mathrm{mPa} . \mathrm{s})$ & - & - & $33,33 \pm 4,62$ \\
Valor energético $(\mathrm{kcal} / 100 \mathrm{~mL})$ & - & - & 79,80 \\
\hline
\end{tabular}

* Média de três repetições; DP - Desvio Padrão; EST - Extrato Seco Total; RMF - Resíduo Mineral Fixo. 


\section{Avaliação da estabilidade físico-química durante a estocagem}

A Tabela 3 apresenta a acidez titulável, $\mathrm{pH}$ e viscosidade da bebida láctea de soro de ricota ao longo do período de 60 dias de estocagem. A análise estatística demonstrou correlação linear inversa significativa entre pH e acidez, e correlação positiva entre $\mathrm{pH}$ e viscosidade. A análise estatística não detectou diferença significativa na acidez titulável, no $\mathrm{pH}$ e na viscosidade aparente em relação ao tempo de estocagem, o que significa que o produto permaneceu estável durante o período de avaliado $(\mathrm{p}>0,05)$.

Ao longo do período de 60 dias de estocagem a bebida apresentou valores acidez média $1,19 \%(\mathrm{~m} / \mathrm{v}), \mathrm{pH} \mathrm{3,71}$ e $33,33 \mathrm{mPa} . \mathrm{s}$ de viscosidade aparente.

Paula (2005) produziu uma bebida à base de soro de leite acidificada, pasteurizada e carbonatada com pH médio de 3,25 e acidez em torno de $1 \%$ de ácido lático, que se apresentou estável sob temperatura ambiente por pelo menos 90 dias. Bastos (2016), desenvolveu uma bebida láctea acidificada carbonatada, com pH 3,77 e acidez média de $1,17 \%(\mathrm{~m} / \mathrm{v})$ de ácido lático, estável por 120 dias à temperatura ambiente. Fontes (2007), desenvolveu uma bebida láctea pasteurizada, tratada termicamente após a fermentação, com pH de 3,4, que permaneceu estável por 35 dias à temperatura ambiente. Luiz (2008) avaliou o efeito do envase à quente na conservação de bebida láctea por 90 dias em temperatura ambiente e empregou um $\mathrm{pH}$ de 3,26 como barreira microbiológica. A literatura e os trabalhos científicos revisados reforçam a necessidade de se aplicar barreiras microbiológicas eficientes para a conservação de bebidas por longos períodos com ou sem refrigeração. Neste trabalho, assim como em vários outros, o pH abaixo de 4,0 foi empregado, o que contribuiu de forma relevante para a estabilidade microbiológica do produto. Outro fator importante é a associação de barreiras, como pH baixo aliado à pasteurização, o que aumenta muito a eficiência do tratamento térmico.

As médias da viscosidade aparente se mostraram semelhantes aos valores apresentados por Bastos (2016), que encontrou a média de $35 \mathrm{mPa}$.s em bebida armazenada sob refrigeração e $28,0 \mathrm{mPa}$.s em bebida mantida em temperatura ambiente.

\section{Avaliação da estabilidade microbiológica}

Não houve crescimento ( $<1 \times 100$ UFC/ $\mathrm{mL}$, estimado) nas contagens dos grupos microbianos avaliados (aeróbios mesófilos, fungos filamentosos e leveduras e coliformes a $30^{\circ} \mathrm{C}$ ou a $45^{\circ} \mathrm{C}$ ) em nenhum dos tempos avaliados segundo a metodologia empregada.

Tabela 3 - Acidez titulável, pH e viscosidade aparente da bebida láctea de soro de ricota, nos tempos 4, 20, 40 e 60 dias de estocagem. As medições foram feitas a $20^{\circ} \mathrm{C}$

\begin{tabular}{cccc}
\hline \multirow{2}{*}{$\begin{array}{c}\text { Tempo } \\
\text { (dias) }\end{array}$} & \multicolumn{3}{c}{ Variáveis (Média \pm Desvio Padrão) } \\
\cline { 2 - 4 } & Acidez titulável $(\%, \mathrm{~m} / \mathrm{v})$ & $\mathrm{pH}$ & Viscosidade $(\mathrm{mPa} . \mathrm{s})$ \\
\hline 4 & $1,22 \pm 0,17$ & $3,71 \pm 0,12$ & 33,33 \\
20 & $1,15 \pm 0,14$ & $3,67 \pm 0,12$ & 32,00 \\
40 & $1,23 \pm 0,14$ & $3,76 \pm 0,11$ & 34,67 \\
60 & $1,17 \pm 0,15$ & $3,68 \pm 0,10$ & 33,33 \\
\hline
\end{tabular}


Essa ausência de contagens se manteve ao longo dos 60 dias de armazenamento sob refrigeração a $5^{\circ} \mathrm{C}$. Assim, pode-se concluir que a bebida láctea está dentro dos limites estabelecidos como critério de aceitação microbiológica preconizada pela legislação (BRASIL, 2005).

Resultados similares também foram encontrados por Bastos (2016), Luiz (2008) e Paula (2005), quando analisadas as contagens de microrganismos durante a avaliação da estabilidade de bebidas lácteas acidificadas armazenadas à temperatura ambiente.

De acordo com os resultados das análises, conclui-se que o produto apresentou estabilidade microbiológica ao longo do tempo de estocagem, comprovando que as barreiras aplicadas foram eficientes para impedir o crescimento dos grupos de microrganismos avaliados durante o período de 60 dias de estocagem sob refrigeração.

\section{Teste de aceitação sensorial}

A Tabela 4 apresenta os resultados referentes aos testes de aceitação, realizados nos tempos 4, 20, 40 e 60 dias de estocagem sob refrigeração.

Tabela 4 - Notas médias dos provadores na escala hedônica de nove pontos durante o tempo de estocagem por 60 dias a $5^{\circ} \mathrm{C}$

\begin{tabular}{cc}
\hline Tempo (dias) & $\begin{array}{c}\text { Bebida de soro de } \\
\text { ricota }(\text { média } \pm \text { DP)* }\end{array}$ \\
\hline 4 & $5,20 \pm 1,92$ \\
20 & $6,28 \pm 1,73$ \\
40 & $6,06 \pm 1,48$ \\
60 & $6,07 \pm 1,84$ \\
\hline
\end{tabular}

* DP - desvio padrão.

Houve uma aceitação mais baixa no primeiro dia de análise (média de 5,20 pontos na escala hedônica de nove pontos). Esta diferença pode ser atribuída ao impacto inicial causado pelo produto nos provadores durante os primeiros dias de análise, levando-se em conta que bebidas carbonatadas produzidas à base de soro não são produtos comuns aos provadores e não existem no mercado produtos similares para fins de comparação ou referência sensorial. Nos demais tempos estudados, o escore que prevaleceu (moda) foi o valor 6 , correspondendo ao termo "gostei ligeiramente".

Pelos resultados fornecidos, é possível assegurar que houve aceitabilidade sensorial dos provadores em relação à bebida láctea acidificada carbonatada, elaborada a partir de soro de ricota. Não foi informado aos provadores sobre as características de baixo custo, tecnologia ou benefícios ao meio ambiente advindos da elaboração desse produto e do aproveitamento do soro de ricota, que é considerado o último soro da indústria de queijos e que é aproveitado de forma ineficiente ou descartado. Vale ressaltar que o painel de provadores foi composto exclusivamente por estudantes do curso técnico em leite e derivados, sendo, portanto, um grupo mais exigente devido ao seu conhecimento tecnológico.

Fontes (2007) utilizou a escala hedônica de nove pontos para avaliar a aceitação sensorial de bebida láctea pasteurizada, com tratamento térmico pós-fermentação, que apresentou os escores médios correspondentes aos termos "gostei ligeiramente" e "gostei muito". Bastos (2016) também utilizou escala hedônica de nove pontos para avaliação sensorial de bebida láctea acidificada carbonatada aromatizada e enriquecida com luteína. A aceitação do produto refrigerado variou entre 6,13 a 6,80 pontos ao longo do tempo de estocagem atingindo média geral de 6,47 pontos, variando entre os termos hedônicos "gostei moderadamente" e "gostei ligeiramente". Paula (2005) desenvolveu uma bebida carbonatada aromatizada à base 
de soro de leite que obteve boa aceitação, situando-se entre os termos hedônicos "gostei moderadamente" e "gostei muito".

\section{CONCLUSÕES}

A utilização do soro de ricota apresenta viabilidade tecnológica e aplicabilidade para a elaboração de bebidas lácteas acidificadas carbonatadas. $\mathrm{O}$ produto se apresentou em conformidade com a legislação podendo ser denominado como bebida láctea com adição. Os resultados das análises físico-químicas, microbiológicas e sensoriais atestaram a estabilidade das bebidas durante 60 dias de armazenamento sob refrigeração a $5^{\circ} \mathrm{C}$, indicando que a metodologia empregada no processamento foi adequada para o desenvolvimento do produto, o que foi comprovado pela estabilidade durante a vida de prateleira e pela aceitação sensorial no período avaliado. No entanto, o grande desafio foi a padronização da composição do soro obtido tanto nas fabricações dos queijos como nas fabricações de ricota e a adequação da formulação da bebida, o que pode aumentar a aceitabilidade sensorial do produto.

Por questões ambientais, econômicas e nutricionais, o uso e aproveitamento de diferentes tipos de soros lácteos, principalmente os desproteinados que não possuem aplicação industrial atualmente no Brasil, é um assunto de extrema importância e que precisa ser discutido em muitos estudos futuros para que seja valorizado e possa aumetar a eficiência de sua utilização.

\section{AGRADECIMENTOS}

À FAPEMIG, pelo financiamento da pesquisa e concessão das bolsas.

\section{REFERÊNCIAS}

ANTUNES, A. J. Funcionalidade de
Proteínas do Soro de Leite Bovino. 1. ed. Barueri: Manole, 2003. 142 p.

BASTOS, G. G. Elaboração e estabilidade de bebida láctea acidificada, carbonatada, aromatizada e enriquecida com luteína. 2016. 56 p. Dissertação (Mestrado Profissional em Ciência e Tecnologia de Leite e Derivados) - Universidade Federal de Juiz de Fora, Juiz de Fora, 2016.

BRASIL. Decreto $n^{\circ} 9.013$, de 29 de março de 2017. Regulamenta a Inspeção Industrial e Sanitária de Produtos de Origem Animal. Diário Oficial da União: seção 1, Brasília, DF, n. 62, p. 3, 30 mar. 2017.

BRASIL. Ministério da Agricultura, Pecuária e Abastecimento. Regulamento Técnico de Identidade e Qualidade de Bebida Láctea. Instrução Normativa $n^{\circ} 16$, de 23 de agosto de 2005. Diário Oficial da União, Seção 1 , p. 7. Brasília, 24 de agosto 2005 .

BRASIL. Ministério da Agricultura, Pecuária e Abastecimento. Secretaria de Defesa Agropecuária. Instrução Normativa $\mathrm{n}^{\circ} 68$, de 12 de dezembro de 2006. Oficializa os Métodos Analíticos Oficiais Físico-Químicos, para Controle de Leite e Produtos Lácteos. Diário Oficial da União: seção 1, Brasília, DF, n. 239, p. 8, 14 dez. 2006.

BRUGNERA, D. F.; Ricota: qualidade microbiológica e o uso de especiarias no controle de Staphylococcus aureus. 2011. 106 p. Dissertação (Mestrado em Ciência dos Alimentos) - Universidade Federal de Lavras, Lavras, 2011.

CHAVES, J. B. P.; SPROESSER, R. L. Práticas de Laboratório de Análise Sensorial de Alimentos e Bebidas. Viçosa: Editora UFV, 1995. 81 p. 
FONTES, A. C. L. Desenvolvimento e avaliação de bebida láctea tratada termicamente após fermentação. 2007. 40 p. Dissertação (Mestrado em Ciência e Tecnologia de Alimentos) - Universidade Federal de Viçosa, Viçosa, 2007.

FURTADO, M. M.; LOURENÇO NETO, J. P. Tecnologia de Queijos: Manual Técnico para a Produção Industrial de Queijos. São Paulo: Dipemar Editora, 1994. 118 p.

HELRICH, K. (ed.). Official Methods of Analysis of the Association of Official Analytical Chemists (AOAC). 15th ed. Arlington: AOAC, 1990.

JAY, J. M.; LOESSNER, M. J.; GOLDEN, D. A. Modern Food Microbiology. 7. ed. New York: Springer, 2005. 790 p. DOI: 10.1007/ b100840

LUIZ, L. M. P. Avaliação do efeito do envase a quente de uma bebida láctea tratada termicamente após fermentação, na sua conservação a temperatura ambiente por até 90 dias. 2008.53 p. Dissertação (Mestrado em Ciência e Tecnologia de Alimentos) Universidade Federal de Viçosa, Viçosa, 2008.

MINIM, V. P. R. Análise Sensorial: estudos com consumidores. Viçosa: Editora UFV, 2006. 225 p.

MINITAB Statistical Software ${ }^{\circledR}$. State College: Minitab, 2011. Disponível em: http:// www.minitab.com/pt-BR/default.aspx.
PARK, Y. W.; KALANTARI, A.; FRANK, J. F. Changes in the microflora of commercial soft goat milk cheese during refrigerated and frozen-storage. Small Ruminant Research, v. 53, p. 61-66. 2004. DOI: 10.1016/j. smallrumres.2003.10.004

PAULA, J. C. J. Elaboração e estabilidade de bebida carbonatada aromatizada à base de soro de leite. 2005. 57 f. Dissertação (Mestrado em Ciência e Tecnologia de Alimentos) Universidade Federal de Viçosa, Viçosa. 2005.

PEREIRA, D. B. C. et al. Físico-Química do Leite e Derivados: Métodos Analíticos. 2.ed. ampl. e rev. Juiz de Fora: Oficina de Impressão Gráfica e Editora, 2001. 234 p.

RAMOS, T. M. Produção de xarope de lactulose a partir do soro de ricota e seu emprego em iogurte e queijo Quark. 2010. 99 p. Dissertação (Mestrado em Ciência dos Alimentos) - Universidade Federal de Lavras, Lavras, 2010.

SANSONETTI, S. et al. Bio-ethanol production by fermentation of ricotta cheese whey as an effective alternative non-vegetable source. Biomass \& Bioenergy, v. 33, n. 12, p.1687-1692, 2009. DOI: 10.1016/j. biombioe.2009.09.002

TEIXEIRA, S. M. B. Elaboração de bebida láctea fermentada utilizando soro de ricota. 2002. 63 p. Dissertação (Mestrado em Ciência dos Alimentos) - Universidade Federal de Lavras, Lavras, 2002. 